American Journal of Applied Sciences 5 (4): 427-434, 2008

ISSN 1546-9239

(C) 2008 Science Publications

\title{
Design and Development of Broadband Inverted E-shaped Patch Microstrip Array Antenna For 3G Wireless Network
}

\author{
${ }^{1,2}$ Norbahiah Misran, ${ }^{3,2}$ Mohammad Tariqul Islam, ${ }^{1} \mathrm{Ng}$ Kok Jiunn \\ ${ }^{1}$ Department of Electrical, Electronics and System Engineering, ${ }^{2}$ Institute for Space Science, Universiti \\ Kebangsaan Malaysia, Bangi 43600, and ${ }^{3}$ Faculty of Engineering and Technology, Multimedia \\ University, Jalan Ayer Keroh Lama, 75450 Melaka, Malaysia
}

\begin{abstract}
Microstrip patch antenna has been received tremendous attention since the last two decades and now it becomes a major component in the development of Smart Antenna System for ThirdGeneration Wireless Network proposed by the ITU-R under the banner of IMT-2000. Smart antenna consists of an array of antennas associated with it a base-band hardware and control unit (inclusive of the software algorithm) that have the capability to change its radiation pattern according to the direction of the user. This paper describes the design and development of broadband Inverted E-shaped patch microstrip array antennas for 3G wireless network. The antenna was designed for the IMT-2000 operating frequency range of $1.885-2.200 \mathrm{GHz}$ and was built as an array of $4 \mathrm{x} 4$ inverted E-shaped patches. The beamforming feed network comprises of commercial variable attenuators (KAT1D04SA002), variable phase shifters (KPH35OSC000), and the corporate 16-ways Wilkinson power divider which was developed in-house. The antenna successfully achieves the bandwidth of $16.14 \%$ (at VSWR: 1.5) with respect to the center frequency of $2.045 \mathrm{GHz}$. The antenna is capable of scanning with the maximum scanning angle of $\pm 30^{\circ}$ and $\pm 25^{\circ}$ in azimuth and elevation respectively.
\end{abstract}

Keywords: 3G, broadband, array, feed network, microstrip antenna

\section{INTRODUCTION}

Wireless communication is widely recognized as one of the fastest growing industries in today's global marketplace ${ }^{[1]}$. As the demand continues to grow, and $(3 \mathrm{G})$ voice and wireless internet services move into the mainstream, wireless operators will be facing a great challenge in providing adequate capacity and high data rate services with a limited amount of radio spectrum into the network as well as maintaining the quality of services. One of the most promising techniques that has the ability to meet the needs for the next generation wireless network is the smart antenna. Research on smart antennas has increased dramatically since 1990's, as the spatial processing has been considered as the last frontier, ${ }^{,[1,2]}$ in the wireless network. Smart antenna technology can significantly improve the performance of the system especially it provides an efficient use of power and spectrum by separating the users through space division multiple access (SDMA) technique ${ }^{[3]}$. The basic principle behind this technique is that the users and interferers had different geographical locations. Thus, by maximizing the antenna gain in the direction of the user and simultaneously placing minimal radiation pattern in the direction of the interferer, the quality of the communication link can be significantly improved ${ }^{[3]}$.

This main feature of a smart antenna can be accomplished by assembling multiple radiating elements in an electrical and geometrical configuration, forming an antenna array. The amplitude and phase excitation (weighting vectors) at each individual radiating element are adjusted to form the beam (beamforming) of the antenna to the desired direction. The required weighting vectors are computed by the control unit that utilizes digital signal processor (DSP) and a software algorithm to bring the intelligence to the antenna.

In designing array antenna, dipole, horn, waveguide slot or microstrip antenna can be used as radiating element. However, microstrip antennas have been proven to be preferable over other types of radiating element due to its non-electrical characteristic. Microstrip antennas are low profile and lightweight. They are also can be made conformal and well suited to integration with microwave integrated circuit. In terms of fabrication, such system offers simplicity, which allows mass production and cost-effective manufacturing as well as high performance $e^{[4,5]}$. However, a conventional patch antenna suffers from very narrow bandwidth ${ }^{[4,5]}$ and this

Corresponding Author: $\quad$ Norbahia Misran, Institute for Space Science, Universiti Kebangsaan Malaysia, 43600 UKM Bangi Malaysia,Tel:+603-89216335,Fax:+60389216146 
pose a challenge for the microstrip antenna designer to meet the proposed broadband IMT-2000 band specification $(1.885-2.200 \mathrm{GHz})$.

In this paper we look into the design and development of a broadband probe fed inverted E-shaped patch microstrip array antennas for $3 \mathrm{G}$ base station wireless network. This paper is discussed the broadband inverted E-shaped radiating element design, the design and development of array antenna.

\section{BROADBAND INVERTED E-SHAPED PATCH RADIATING ELEMENT DESIGN}

Recently, a novel single layer wide-band rectangular patch antenna with achievable impedance bandwidth of greater than $20 \%$ has been demonstrated $^{[6-8]}$. This single-layer wideband microstrip antenna retains the thin-profile and small size characteristics and does not introduce grating-lobe problems when used in an array environment ${ }^{[6]}$.

$\mathrm{In}^{[6]}$, the authors embedded a U-slot in the rectangular patch with achievable bandwidth of 10$40 \%$. In $^{[7]}$ and ${ }^{[8]}$, an E-shape (or a pair of wide slit) rectangular patch with a simpler construction compared to the U-slot microstrip antenna, demonstrated a bandwidth enhancement of $24 \%$ and $30.3 \%$ respectively. In these design, an air-filled or foam substrate has been essential to realize the broadband characteristic. However, these structures pose a fabrication problem, especially, when it is to be applied to an array structure.

In this paper, a broadband inverted E-shaped rectangular microstrip patch antenna using two dielectric layers approach has been developed to support the IMT-2000 band. Much of the material in this section are extracted from our previous publication $^{[9]}$, however in this paper the discussion cover the aspect of the radiation pattern which is not concluded in the earlier paper.

The design uses a low permittivity dielectric supporting the inverted radiating E-shaped patch above a ground plane with an air-filled substrate sandwiched between them. The design meets the broadband bandwidth requirement of better than $15.42 \%$ at $14-\mathrm{dB}$ return loss. Apart from maintaining the broadband characteristic of the antenna, the thick air-filled substrate sandwiched between the ground plane and the patch eased the probe feeding to the patch. In addition, by employing the air-filled substrate, the substrate thickness can be adjusted easily in the design by adjusting the spacer and it is more cost effective.
Further the design facilitates the fabrication of the patch using the printed circuit board (PCB) technique.

The geometry of the probe-fed inverted E-shaped rectangular patch antenna is shown in Fig. 1. The patch with a width $W$ and length $L$ is supported by a low dielectric superstrate with dielectric constant $\varepsilon_{1}$ and thickness $h_{l}$. An air-filled substrate with dielectric constant $\varepsilon_{0}$ and thickness $h_{o}$ is sandwiched between the superstrate and a ground plane. The radiating patch is fed by a probe along the centerline (y-axis) of the patch at a distance $f p$ from the bottom edge of the patch as shown in the figure. Two parallel slots with slot length, width, and spacing between slots, $l s, w s$, and $s$ respectively are incorporated onto the rectangular patch, symmetrically with respect to the centerline.

The inverted E-shaped rectangular patch antenna was fabricated, simulated using Sonnet em simulator, and measured using the Agilent PNA E8358A network analyzer in the open field. The slot parameters, $l s, s, w s$, and the thickness of the air-filled substrate, $h_{o}$ are adjusted to obtain an optimum design performance. In this work we used Sonnet em simulator to simulate the design. The optimized parameters of the broadband probe-fed inverted E-shaped patch antenna are given in Table I.

Table 1: Optimize Parameters for Broadband Inverted E-Shaped Patch Antenna

\begin{tabular}{l|l}
\hline Superstrate & RT $5880\left(\varepsilon_{l}=2.2, h_{l}=1.5748 \mathrm{~mm}\right)$ \\
\hline Substrate & Air $\left(\varepsilon_{0}=1, h_{0}=12.5 \mathrm{~mm}\right)$ \\
\hline $\begin{array}{l}\text { Rectangular } \\
\text { patch }\end{array}$ & Width and Length, $\{W, L\}=\{79,53\} \mathrm{mm}$ \\
\hline $\begin{array}{l}\text { Feed } \\
\text { Position, }\end{array}$ & $f p=13.5 \mathrm{~mm}$ frombottomedge along $\mathrm{y}-$ \\
\hline $\begin{array}{l}\text { Slots } \\
\text { parameters }\end{array}$ & $\{l s, s, w s\}=\{47,15,10\} \mathrm{mm}$ \\
\hline
\end{tabular}

The inverted E-shaped patch is fabricated on Rogers RT 5880 with dielectric permittivity, $\varepsilon_{r}$ of 2.2 and with thickness, $h_{l}$ of $1.5748 \mathrm{~mm}$. The thickness of the air-filled substrate, $h_{o}$ is $8.56 \%$ of the center frequency wavelength at $2.054 \mathrm{GHz}$. An Aluminum plate with dimensions of 200x180 mm and thickness of $1 \mathrm{~mm}$ is used as a ground plane. Fig. 2 shows the photograph of the antenna. The fabricated inverted Epatch and the ground plane are fastened together using silicon spacers and screws ( $3 \mathrm{~mm}$ dia.). The direction of the E-plane and H-plane are superimposed on the image as shown in Fig. 2(a). 


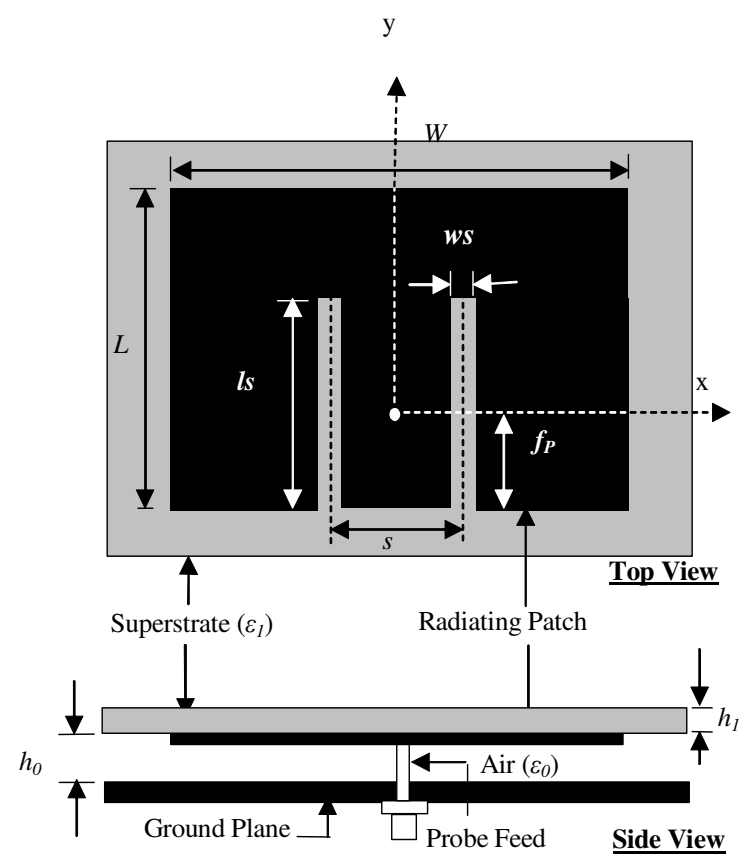

Fig. 1: Geometry of the inverted E-Shaped rectangular patch antenna

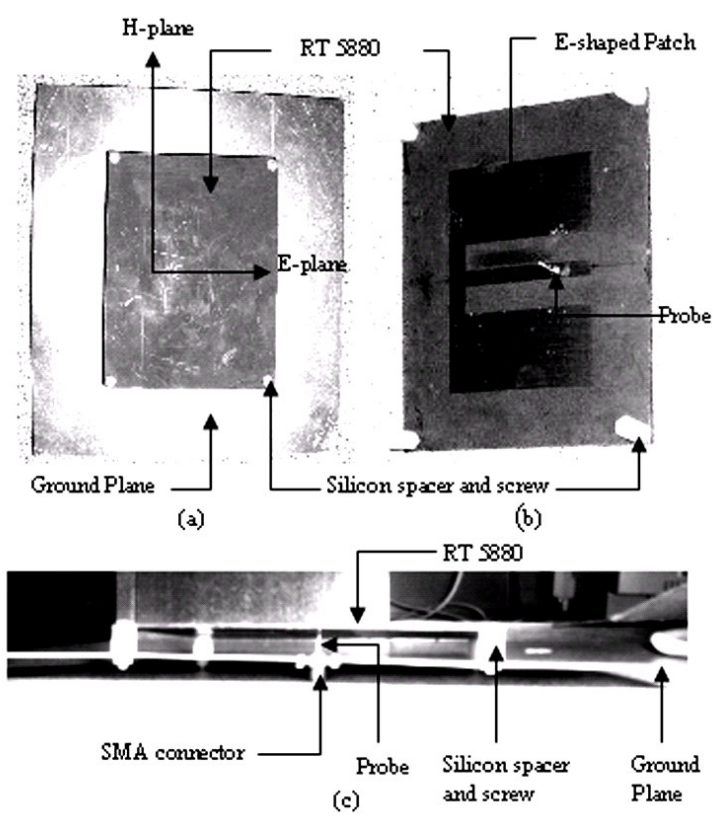

Fig. 2: A photo of the inverted E-shaped patch antenna design: (a) top view, (b) the inverted E-shaped patch and, (c) side view
The measurement and simulation results of the return loss of the antenna are shown in Fig. 3. Both the simulated and measured results are shown to be in good agreements. Noted in the figure, the antenna resonates at $1.93 \mathrm{GHz}$ and at $2.13 \mathrm{GHz}$, where these closely excited adjacent resonant frequencies resulted in a broadband characteristic of the antenna. These dualresonance frequencies are due to the effect introduced by the embedded parallel slots structure of the rectangular patch.

As shown in Fig. 3, the measured impedance bandwidth of $18.91 \%$ is obtained, covering the frequency range from 1.86 to $2.25 \mathrm{GHz}$, while the simulated patch gives a slightly lower impedance bandwidth of $17.56 \%$, at the center frequency of 2.05 GHz. These impedance bandwidth values are determined at return loss level of $14 \mathrm{~dB}(\mathrm{SWR}=1.5)$. For $10 \mathrm{~dB}$ return loss $(\mathrm{SWR}=2)$, the measured bandwidth is $22.65 \%$. Table II summarized the results of the simulated and measured parameters of the antenna.

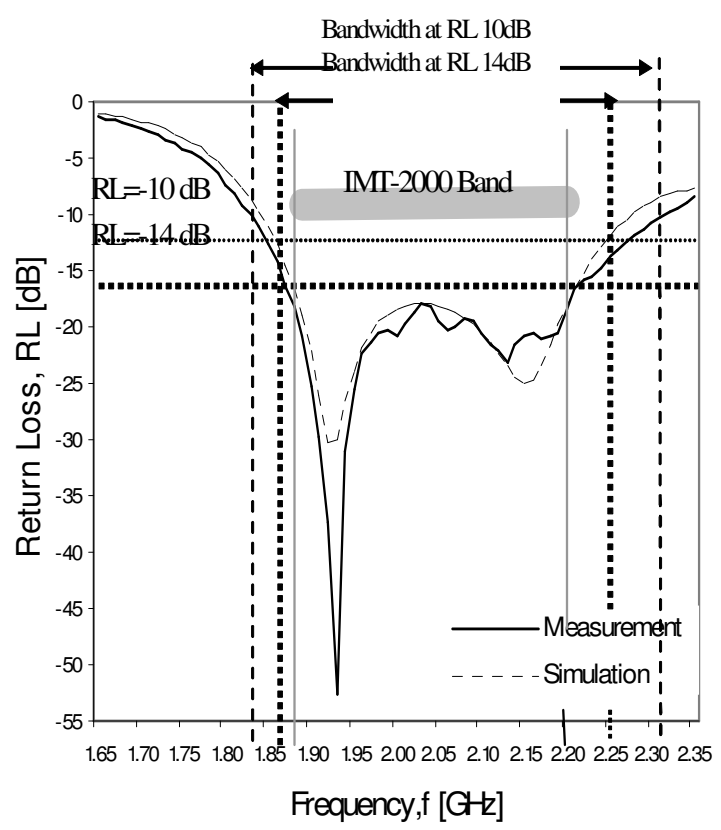

Fig. 3: Measured and simulated Return loss of the antenna 
Table 2: Comparison Between Simulation Result And Measurement Result

\begin{tabular}{lcc}
\hline Properties & $\begin{array}{c}\text { Simulation } \\
\text { Result }\end{array}$ & $\begin{array}{c}\text { Measurement } \\
\text { Result }\end{array}$ \\
\hline Frequency Range & $1.87-2.23$ & $1.86-2.25$ \\
\hline Bandwidth (with & $360 \mathrm{MHz}$ & $388.5 \mathrm{MHz}$ \\
the VSWR 1.5) & $(17.56 \%)$ & $(18.91 \%)$ \\
\hline Center Frequency & $2.05 \mathrm{GHz}$ & $2.05 \mathrm{GHz}$ \\
\hline Resonance & At: $1.92 \mathrm{GHZ}$, & At: $1.93 \mathrm{GHz}$, \\
Frequency & VSWR: 1.07 & VSWR: 1.02 \\
& At: $2.15 \mathrm{GHZ}$, & At : $2.13 \mathrm{GHz}$, \\
& VSWR: 1.12 & VSWR: 1.14 \\
\hline
\end{tabular}

Our designed antenna gave a much narrower bandwidth compared to the design demonstrated in ${ }^{[6-8]}$. This is due to the fact that our antenna is designed to give a better return loss by optimizing the slots to excite at a closer resonance frequencies, without sacrificing the bandwidth requirement of the IMT-2000 band.

The radiation characteristics of the antenna measured in free space range are shown in Fig. 4 and Fig. 5. Fig. 4 shows the E-plane radiation pattern of the patch at resonance frequencies of $1.93 \mathrm{GHz}$ and $2.13 \mathrm{GHz}$. The $3-\mathrm{dB}$ beamwidth at these frequencies are closed to $80^{\circ}$ and $75^{\circ}$ respectively. At these frequencies, the measured peak cross polarization of the pattern is $-12.03 \mathrm{~dB}$ and $-11.34 \mathrm{~dB}$ respectively.

The H-plane radiation pattern of the patch is presented in Fig. 5. It shows a slightly broader beamwidth of about $90^{\circ}$ and $85^{\circ}$ respectively at 1.93 $\mathrm{GHz}$ and $2.13 \mathrm{GHz}$. The radiation pattern is virtually symmetry in the H-plane but asymmetries in the Eplane. These results are similar to the report of a thick substrate rectangular patch antenna by Chang et al. ${ }^{[10]}$. Noted in this figure, the cross polarization in the $\mathrm{H}-$ plane is considerably higher than the E-plane, with the peak cross polarization of $-6.88 \mathrm{~dB}$ and $-5.47 \mathrm{~dB}$ at the resonance frequencies. Similar observations have been reported in the literature ${ }^{[8]}$. The high cross-polarization of the antenna is generally due to the leaky radiation of the $\operatorname{slot}^{[8]}$ and also the substrate thickness ${ }^{[11]}$. In ${ }^{[11]}$, the analysis of the cross-polarization characteristic of a probe fed rectangular patch antenna shows that the cross polarization level increases with resonant frequency and thickness. Therefore the higher crosspolarization measured at high resonant frequency in both E- and H-plane agrees with the analysis demonstrated in ${ }^{[11]}$.

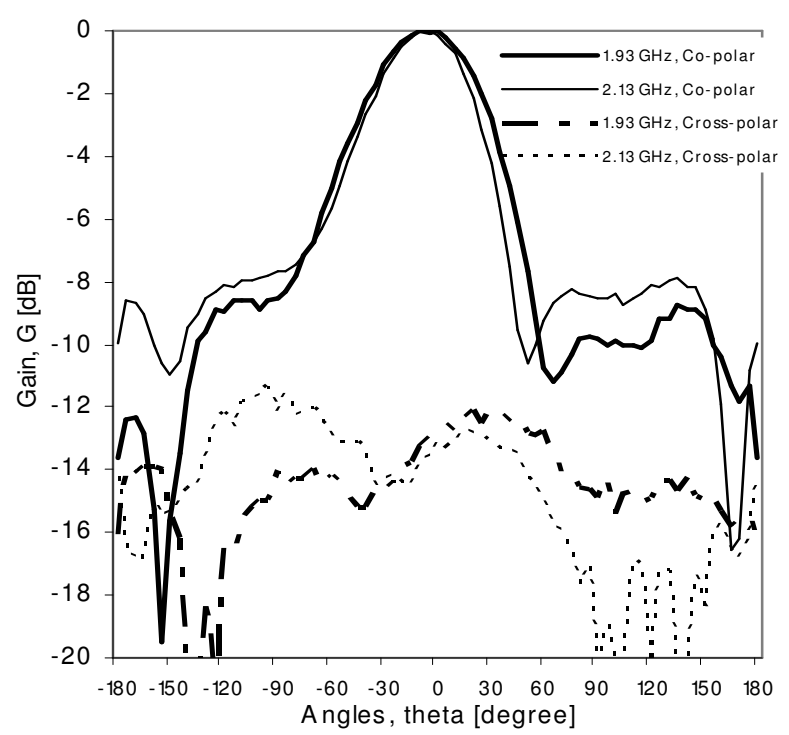

Fig. 4: Measured normalized E-plane radiation pattern of the E-shaped rectangular patch antenna

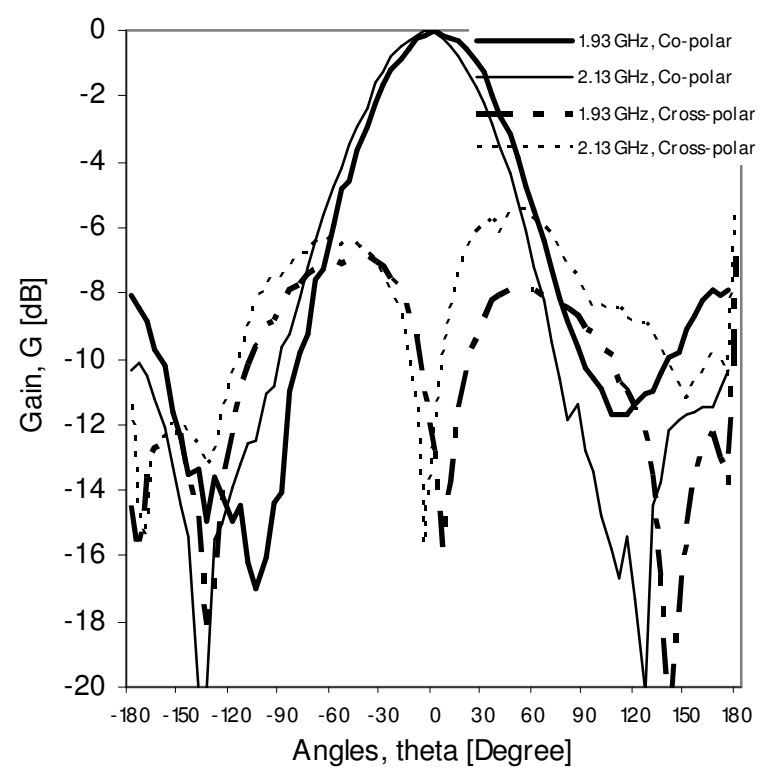

Fig. 5: Measured normalized H-plane radiation pattern of the E-shaped rectangular patch antenna

Fig. 6 shows the measured gain at different frequencies. The maximum gain is about $10.36 \mathrm{~dB}$ and the gain variation in the region of the operating frequency is about $1.9 \mathrm{~dB}$ which is inside the $3 \mathrm{~dB}$ gain band. 


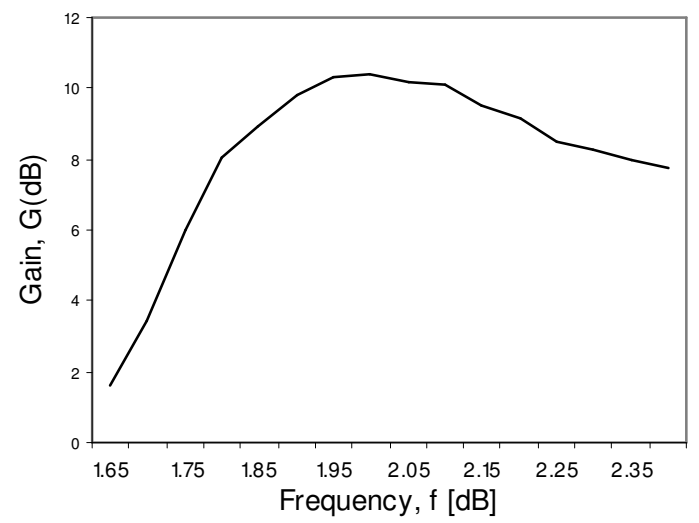

Fig. 6: Measured gain of the E-shaped rectangular patch antenna at different frequency

\section{DESIGN AND DEVELOPMENT OF ARRAY ANTENNA}

The building block of the array antenna is shown in Fig. 7. It comprises of the $4 \times 4$ elements array to feed the beamforming feed network (network of variable attenuators, variable phase shifters and 16 ways corporate feed).

Inverted E-shaped patch array design:The radiating element, the inverted E-shaped patch antenna was arranged in a $4 \times 4$ planar array configuration as shown in Fig. 8. The elements are spaced at $0.6 \lambda_{0}(\mathrm{dx})$ and $0.7 \lambda_{0}(\mathrm{dy})$ with $\lambda_{0}=136 \mathrm{~mm}$ (at frequency of $2.2 \mathrm{GHz}$ ). This configuration enables the arrays to scan at the maximum scanning angle of $30^{\circ}$ in the E-plane and $25^{\circ}$ in the H-plane respectively.

The $4 \times 4$ inverted E-shaped patches are fabricated on a superstrate RT $5880\left(W_{\mathrm{RT} 5580}=340 \mathrm{~mm}, L_{\mathrm{RT} 5580}\right.$ $=404 \mathrm{~mm}, \varepsilon r_{\text {RT5580 }}=2.2$, and $h_{\text {RT5580 }}=1.5748 \mathrm{~mm}$ ). The superstrate is supported with silicon spacers (12.7 $\mathrm{mm}$ height and $3 \mathrm{~mm}$ dia.) above the aluminum ground plane $(420 \times 484 \times 1 \mathrm{~mm})$. The elements are fed to a beamforming feed network which comprises of a commercial variable phase shifters (KPH350SC00 @ KMW Inc), step-rotary attenuators (KATID04SA002@KMW Inc) and an in-house designed 16-ways Wilkinson power divider. Fig. 9 shows the fabricated $4 \times 4$ inverted E-shaped patch array.

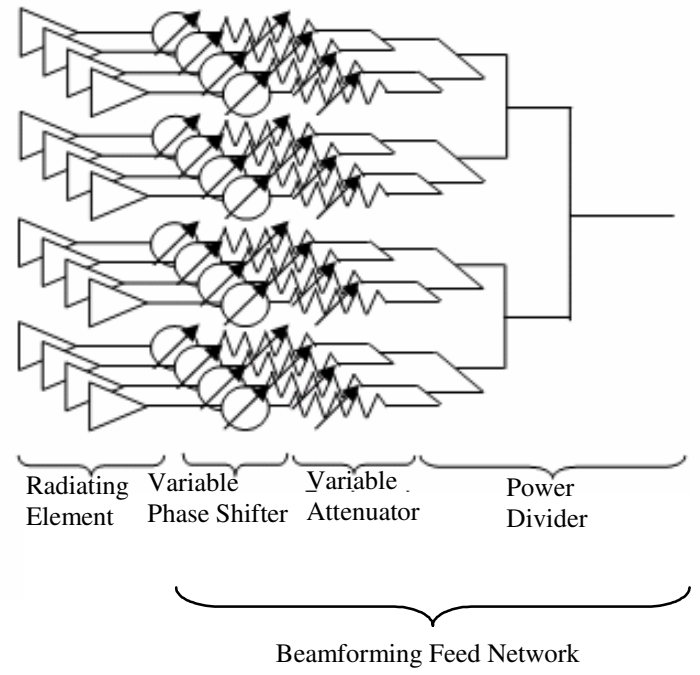

Fig. 7: Building block of a planar array antenna

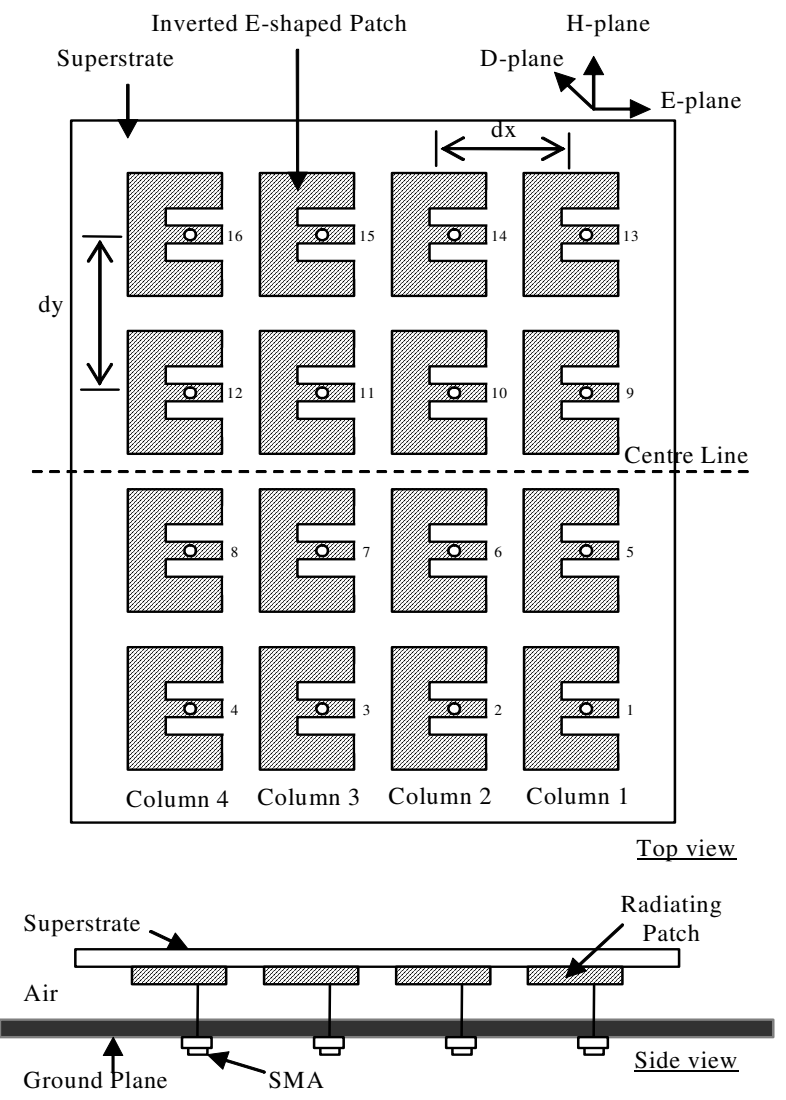

Fig. 8: The Geometry of $4 \times 4$ inverted E-shaped patch planar array 


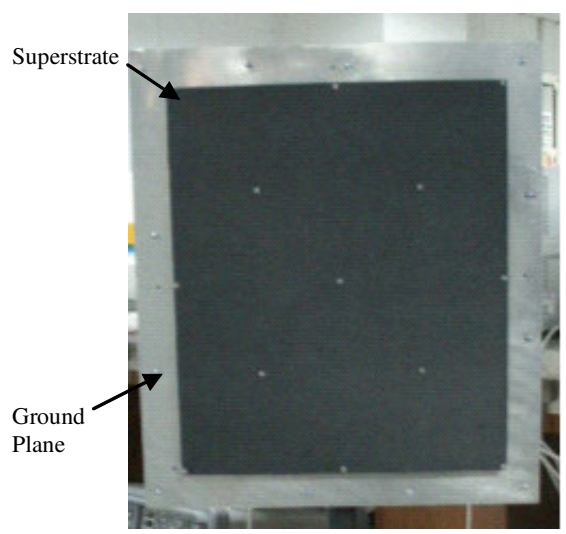

(a)

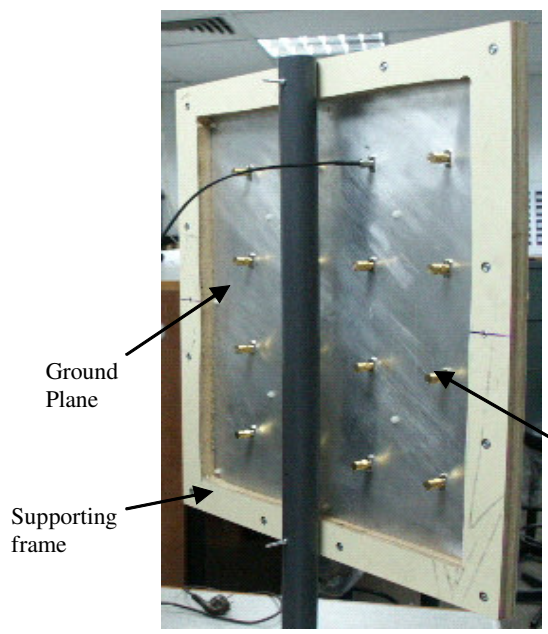

(b)

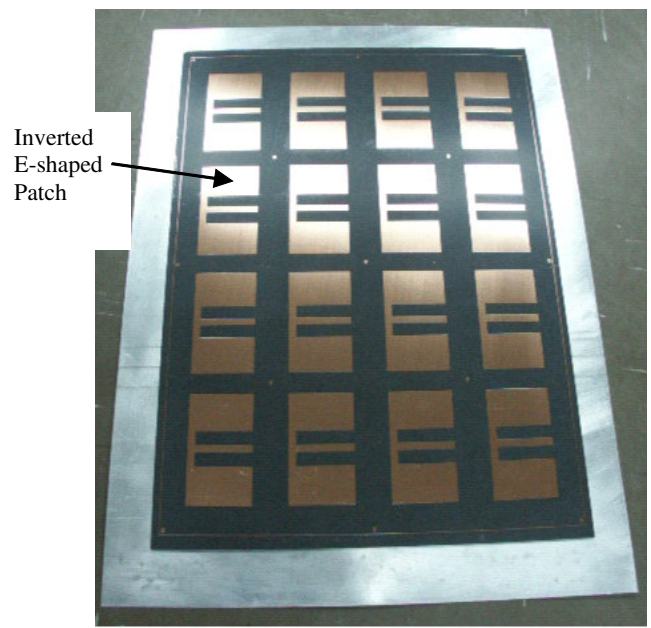

(c)

Fig. 9: The developed $4 \times 4$ inverted E-shaped patch array antenna

\section{RESULTS AND DISCUSSION}

The measurement of the return loss was carried out by using PNA E8358A. Mutual coupling of the arrays are simulated and measured. Radiation pattern characteristic are measured using Agilent E4436B signal generator and Advantest R3131A spectrum analyzer in the open field.

Return Loss: The measurements of return loss of each element in the array are necessary due to the differences in their input impedances caused by the mutual coupling effects. This impedance mismatched can defect to the radiation pattern of the antenna array. As the radiating elements are symmetrical along the centre line, therefore pairs of element will show similar results and will be represented by pairing results.

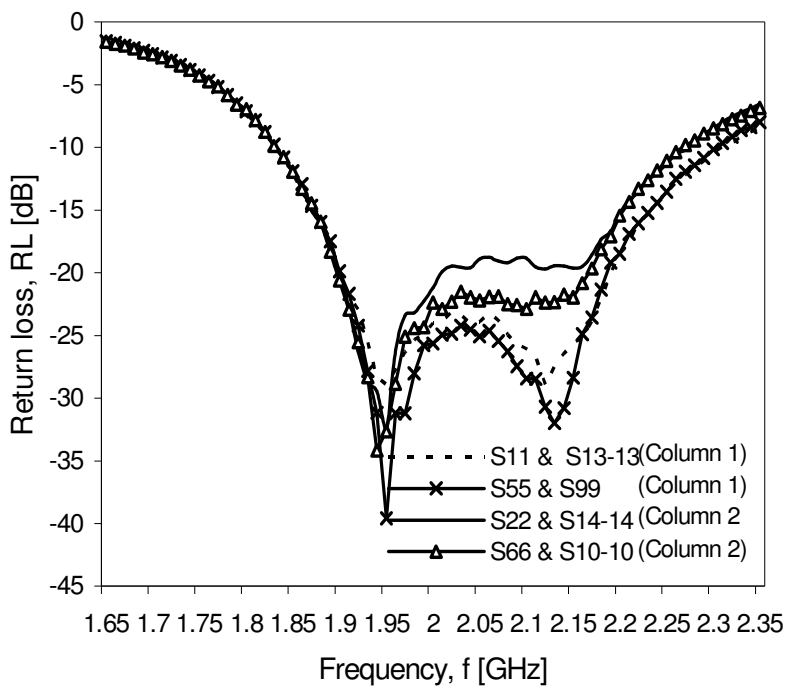

Fig. 10: Return loss of the inverted E-shaped patch elements in column 1 and 2 in the $4 \times 4$ array

Fig. 10 and Fig. 11 show the measured return loss for the elements in the first two columns and the remaining columns respectively. Simulation results agree well to the measured results but are not presented for the sake of brevity.

Radiation pattern: Fig. 12 shows the measured Eplane radiation pattern for the $4 \times 4$ inverted E-shaped patch array antenna with the Chebyshev amplitude distribution. Chebyshev amplitude distribution is used in the 


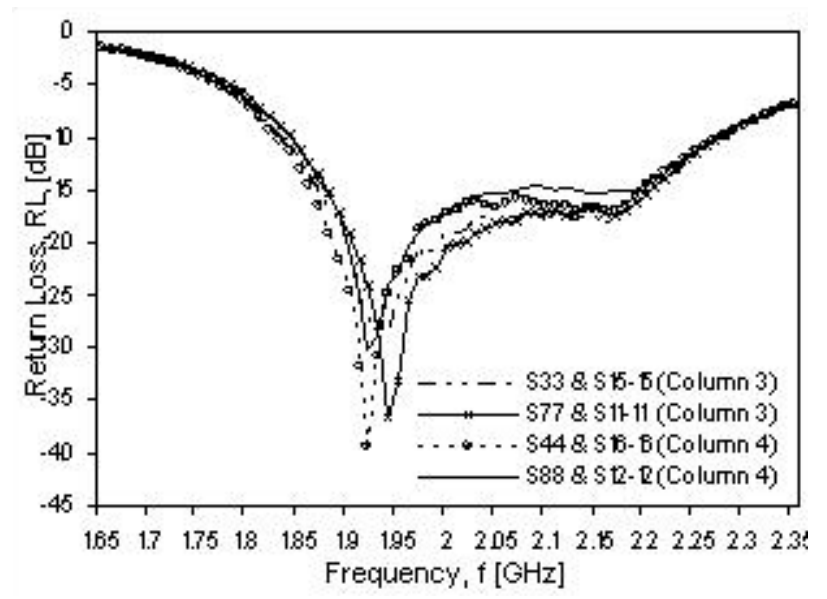

Fig. 11: Return loss of the inverted E-patch elements in column 3 and 4 in the $4 \times 4$ array

design to provide narrow beamwidth and with low equal side lobe level $(-20 \mathrm{~dB})$. The radiation pattern of the array exhibits an asymmetry in the E-plane with unequal side lobe levels. Higher side lobe levels is observed at angle $\theta$ between $-35^{\circ}$ and $-45^{\circ}$ with side lobe levels of $16.32 \mathrm{~dB}$ and $17.48 \mathrm{~dB}$ at $19.4 \mathrm{GHz}$ and $2.13 \mathrm{GHz}$ respectively. This higher side lobe levels result is due to the amplitude/phase unbalances in the beamforming feed network.

Fig. 13 presents the measured $\mathrm{H}$-plane radiation pattern for the $4 \times 4$ inverted E-shaped patch array antenna with the Chebyshev amplitude distribution. In H-plane, the side lobe level is $-17.94 \mathrm{~dB}$ and $18.67 \mathrm{~dB}$ at both resonance frequencies. The $3-\mathrm{dB}$ beamwidth is measured to be around $25^{\circ}$ at both resonance frequencies $(1.94 \mathrm{GHz}$ and $2.13 \mathrm{GHz})$ in E-plane and H-plane. The maximum cross polarization is of the order of $20-35 \mathrm{~dB}$ in the Eplane and 15-20 dB in the H-plane.

The gain variation of the array at different frequencies is shown in Fig. 14. The maximum gain of the array antenna is $13.14 \mathrm{~dB}$ at $2.05 \mathrm{GHz}$. The gain variation of the array in the operating frequency range is observed to be around $1.51 \mathrm{~dB}$.

\section{CONCLUSION}

In this paper, the design and development of $4 \times 4$ elements inverted E-shaped microstrip patch array antenna for $3 \mathrm{G}$ wireless network is presented. The design of the array utilizes two embedded slot onto the rectangular patch to excite two closely resonance frequencies which contributes to broadband characteristic. The patch is fabricated inversely for ease fabrication, gain enhancement as well as protecting the patch from environment. The measured impedance bandwidth of inverted Eshaped microstrip patch element is $18.91 \%$, covering the frequency range from 1.86 to $2.25 \mathrm{GHz}$.

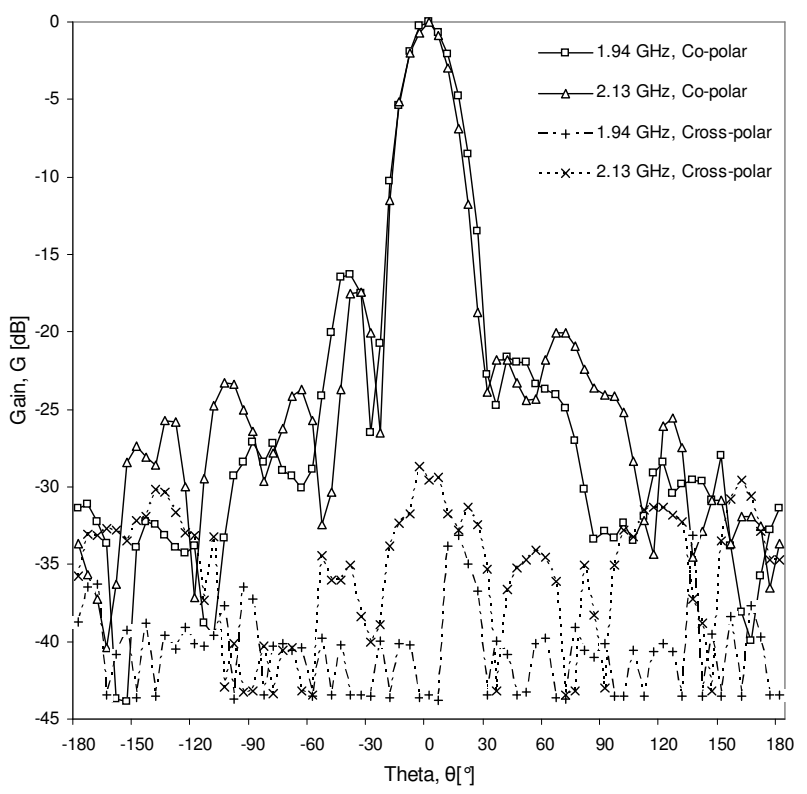

Fig. 12: The E-plane radiation pattern of the $4 \times 4$ inverted E-shaped patch array antenna with Chebyshev amplitude distribution

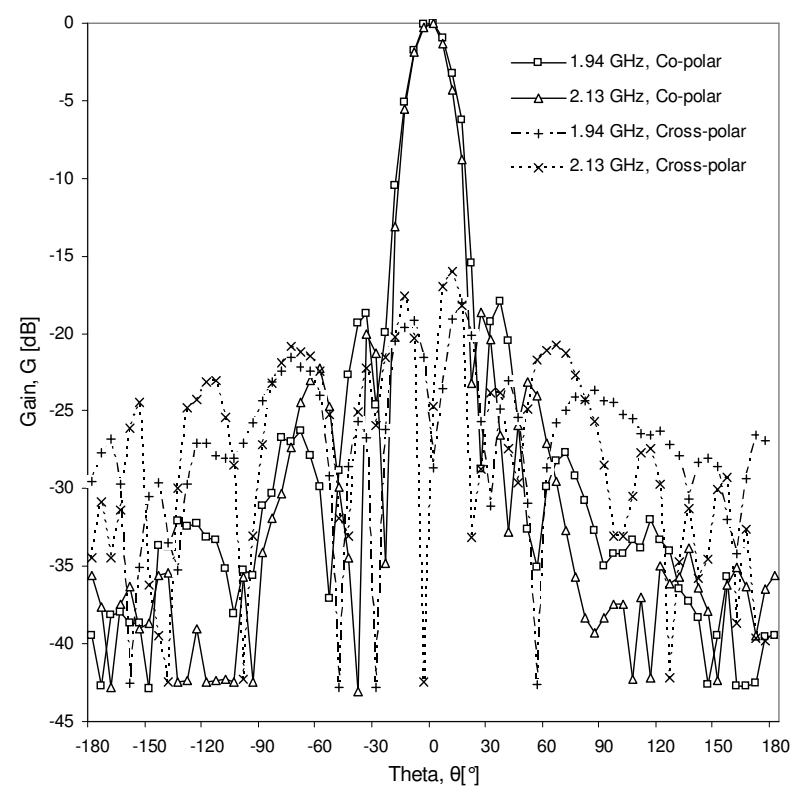

Fig. 13: The H-plane radiation pattern $4 x 4$ inverted E-shaped patch array antenna with Chebyshev amplitude distribution 


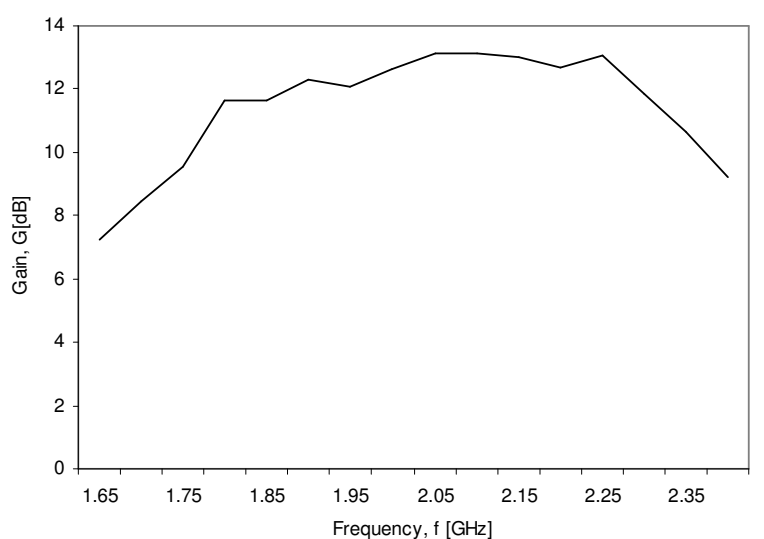

Fig. 14: The $4 \times 4$ inverted E-shaped patch array antenna gain pattern with Chebyshev amplitude distribution at different frequencies

The inverted E-shaped patch antenna was arranged in a $4 \times 4$ planar array configuration. This configuration enables the arrays to scan at the maximum scanning angle of $30^{\circ}$ in the E-plane and $25^{\circ}$ in the H-plane respectively. The elements are fed to a beamforming feed network which comprises of a commercial variable phase shifters (KPH350SC00 @ KMW Inc), step-rotary attenuators (KATID04SA002 @ KMW Inc) and an in-house designed 16-ways Wilkinson power divider. A prototype of the array has been fabricated and measured. The prototype achieved the measured bandwidth of $16.14 \%$ (RL = $14 \mathrm{~dB}$ ) covering the IMT-2000 band.

Chebyshev amplitude distribution is used in the design to provide narrow beamwidth and with low equal side lobe level. The E-plane radiation pattern exhibits side lobe levels of $16.32 \mathrm{~dB}$ and $17.48 \mathrm{~dB}$ at $19.4 \mathrm{GHz}$ and $2.13 \mathrm{GHz}$ respectively. In H-plane, the side lobe level is $-17.94 \mathrm{~dB}$ and $-18.67 \mathrm{~dB}$ at both resonance frequencies. The $3-\mathrm{dB}$ beamwidth is measured to be around $25^{\circ}$ at both resonance frequencies $(1.94 \mathrm{GHz}$ and $2.13 \mathrm{GHz})$ in E-plane and $\mathrm{H}$-plane. The maximum cross polarization is of the order of 20-35 dB in the E-plane and 15-20 dB in the $\mathrm{H}$-plane. The gain variation of the array in the operating frequency range is observed to be around $1.51 \mathrm{~dB}$.

\section{ACKNOWLEDGEMENTS}

The authors would like to thank the IRPA Secretariat, Ministry of Science, Technology and Environmental of Malaysia, for sponsoring this work. This work is funded by IPRA 04-02-02-0029.

\section{REFERENCES}

1. R. H. Roy. Application of Smart Antenna Technology in Wireless Communication Systems. ArrayComm White Paper URL:http://www.arraycomm.com/Company/white _papers.html

2. P.H. Lehne \& M. Pettersen. 1999. An Overview of Smart Antenna Technology for Mobile Communications System. IEEE communications Survey, URL: Http://www.comsoc.org/pubs/ surveys, Fourth Quarter, 2(4).

3. A. O. Boukalov \& S-G. Häggman. 2000. System aspect of smart-antenna technology in cellular wireless communications - An overview. IEEE Trans. Antennas Propagat., 48(6): 919-929.

4. K.-L, Lau, , K.-M., Luk and K.-F., Lee. 2006. Design of a circularly-polarized vertical patch antenna. IEEE Transactions on Antennas and Propagation, 54(4): 1332- 1335.

5. Y.P., Zhang and J.J. Wang. 2006. Theory and analysis of differentially-driven microstrip antennas. IEEE Transactions on Antennas and Propagation, 54(4): 1092-1099.

6. T. Huynh and K. F. Lee. 1995. Single-layer singlepatch wideband microstrip antenna. Electron. Lett., 31(16): 1310-1312.

7. K.-L Wong and W.-H Hsu. 2001. A broad-band rectangular patch antenna with a pair wide slits. IEEE Trans. Antennas Propagat., 49(9):1345-1347.

8. F. Yang, X.-X. Zhang, X. Ye, and Y. RahmatSamii. 2001. Wide-band E-shaped patch antennas for wireless communications. IEEE Trans. Antennas Propagat., 49(7): 1094-1100.

9. K. J. Ng, Z. A. Abdul Rashid and M. Tariqul Islam. 2003. Broadband Inverted E-shaped Rectangular Microstrip Patch Antennas for 3G Applications. IEEE National Symposium on Microelectronics (NSM 2003), 286-289.

10. ES. Chang, S. A. Long and W. F. Richards. 1986. An experimental Investigation of Electrically Thick Rectangular Microstrip Antennas. IEEE Trans. Antennas Propagat., 34(6): 767-772.

11. T. Huynh, K. F. Lee, and R. Q. Lee. 1998. Cross polarization Characteristic Rectangular Patch Antennas. Electron. Lett., 24: 463-464. 